\title{
1200 years of warm-season temperature variability in central Scandinavia inferred from tree-ring density
}

\author{
Peng Zhang ${ }^{1}$, Hans W. Linderholm ${ }^{1}$, Björn E. Gunnarson ${ }^{2}$, Jesper Björklund ${ }^{3}$, and Deliang Chen ${ }^{1}$ \\ ${ }^{1}$ Regional Climate Group, Department of Earth Sciences, University of Gothenburg, Gothenburg, Sweden \\ ${ }^{2}$ Bolin Centre for Climate Research, Department of Physical Geography, Stockholm University, Stockholm, Sweden \\ ${ }^{3}$ Swiss Federal Research Institute WSL, Birmensdorf, Switzerland \\ Correspondence to: Peng Zhang (peng.zhang@gvc.gu.se)
}

Received: 12 January 2015 - Published in Clim. Past Discuss.: 19 February 2015

Revised: 30 April 2016 - Accepted: 15 May 2016 - Published: 3 June 2016

\begin{abstract}
Despite the emergence of new high-resolution temperature reconstructions around the world, only a few cover the Medieval Climate Anomaly (MCA). Here we present C-Scan, a new Scots pine tree-ring density-based reconstruction of warm-season (April-September) temperatures for central Scandinavia back to $850 \mathrm{CE}$, extending the previous reconstruction by 250 years. C-Scan is based on samples collected in a confined mountain region, adjusted for their differences in altitude and local environment, and standardised using the new RSFi algorithm to preserve lowfrequency signals. In C-Scan, the warm peak of MCA occurs ca. 1000-1100 CE, and the Little Ice Age (LIA) between 1550 and 1900 CE. Moreover, during the last millennium the coldest decades are found around $1600 \mathrm{CE}$, and the warmest 10 and 30 years occur in the most recent century. By comparing C-Scan with other millennium-long temperature reconstructions from Fennoscandia, regional differences in multi-decadal temperature variability, especially during the warm period of the last millennium are revealed. Although these differences could be due to methodological reasons, they may indicate asynchronous warming patterns across Fennoscandia. Further investigation of these regional differences and the reasons and mechanisms behind them are needed.
\end{abstract}

\section{Introduction}

In order to assess the role of human activities in current climate change (Bindoff et al., 2013), numerous efforts have been made to place the present warming in a longer-term context (e.g. Wilson et al., 2016). Despite these attempts, there are still controversies about past climate. For example, present-day global mean air temperatures may have been equally high around 1000 years ago during the so-called Medieval Climate Anomaly (MCA; Lamb, 1969; Grove and Switsur, 1994). However, since regional temperature reconstructions display large variability in the timing and magnitude of the MCA (PAGES 2k Consortium, 2013), this issue has not yet been adequately settled. Hence, there is still a great need to produce and improve empirical proxy data to further our understanding of near and distant climate changes.

Tree-rings are widely recognised as an excellent proxy of past climate due to their sensitivity to growing-season conditions, and their annual resolution with absolute dating (Briffa et al., 2001). The high-latitude region of Fennoscandia in northwest Europe is well-suited to dendrochronological research, with large tracts of relatively accessible boreal forests and some of the world's most temperature-sensitive conifers (St. George, 2014) in combination with favourable preservation-conditions for deadwood. These make the region well-suited for developing long tree-ring chronologies, extending back over the past millennia (Linderholm et al., 2010). In addition to the multi-millennial tree-ring width chronologies from Torneträsk (Grudd et al., 2002), Finnish Lapland (Helama et al., 2002, 2008) and Jämtland (Gunnarson et al., 2003), several millennium-long tree-ring data sets were produced within the EU funded "Millennium" project (McCarroll et al., 2013). We stress that, compared to ring width, maximum latewood density (MXD) or the recently developed $\Delta$ Density method (Björklund et al., 2014, 2015), are preferred warm-season temperature proxies. In Fennoscan- 
dia, most of the sampling for millennium-long temperature reconstructions has focused on regions close to the latitudinal tree limit (Esper et al., 2012; McCarroll et al., 2013; Melvin et al., 2013). However, to better represent the whole of Fennoscandia, data from more southerly locations are also needed (Linderholm et al., 2015). Indeed, a few studies have produced long reconstructions from more southerly sites. Helama et al. (2014) reconstructed May-September temperature variability in southern Finland (around $61^{\circ} \mathrm{N}$ ) for the last millennium using MXD data. In Sweden, MXD from Jämtland $\left(63^{\circ} \mathrm{N}\right.$; Gunnarson et al., 2011; henceforth G11, referring to the temperature reconstruction), minimum blue intensity from Mora $\left(61^{\circ} \mathrm{N}\right.$; Graham et al., 2011) and adjusted $\Delta$ blue intensity from Jämtland and Arjeplog (63 and $65^{\circ} \mathrm{N}$; Björklund et al., 2015) have been used to infer past warm-season temperatures, but these reconstructions cover only the last $800-900$ years.

The primary aim of this study is to extend G11 back in time to cover the MCA. G11 contains a mix of data: tree-line samples collected in 2006, as well as samples from historical buildings in west-central Sweden, collected in the late 1980s as a part of an archaeological survey by Kvartärbiologiska Laboratoriet in Lund, Sweden. The historical samples cover the period 1107-1827 CE (gap during 1292-1315 CE), and the tree-line samples cover the period 1292-2006 CE. The geographical origins of some of the historical samples in G11 are unclear, but they likely come from lowland locations, about $300 \mathrm{~m}$ below the present tree-line, and are thus suboptimal for temperature reconstruction (Fritts, 1976). Therefore, we aim to replace the historical samples with samples collected from past and present tree-line environments where the provenance is known. Using this new reconstruction, we re-examine the warm-season temperature evolution in central Scandinavia during the last 1150 years, and compare it to other reconstructions from northern and eastern Fennoscandia (Melvin et al., 2013; Esper et al., 2012; Helama et al., 2014). This improved data set allows us to provide new insights into temperature variability during the last millennium in central Scandinavia.

\section{Data and methods}

\subsection{Study area}

The study area is located in the province of Jämtland, east of the main divide of the Scandinavian Mountains in westcentral Sweden. Due to the geographical setting, there is a distinct climate gradient in the region (Linderholm et al., 2003). East of the Scandinavian Mountains, climate can be described as semi-continental. However, the proximity to the Norwegian Sea, lack of high mountains in the west, and the east-west oriented valleys allow moist air to be advected from the ocean, providing an oceanic influence to the area (Johannessen, 1970; Johansson and Chen, 2003; Bojariu and Giorgi, 2005). Consequently, the study area is a border zone between oceanic and continental climates (Wallén, 1970). On short timescales, the climate of this area is influenced by the North Atlantic Oscillation (NAO; Chen and Hellström, 1999; Busuioc et al., 2001; Folland et al., 2009), while it is affected by North Atlantic sea-surface temperature (SST) on longer timescales (Rodwell et al., 1999; Rodwell and Folland, 2002). The elevation of the area ranges from 800 to $1000 \mathrm{~m}$ a.s.l., and scattered alpine massifs to the south reach approximately 1700 ma.s.l. Glacial deposits dominate the area, mainly till but also glaciofluvial deposits, peatlands and small areas of lacustrine sediments (Lundqvist, 1969). Pinus sylvestris L. (Scots pine), Picea abies (L.) H. Karst. (Norway spruce) and Betula pubescens, Ehrh. (Mountain birch) are the main tree species in the central Scandinavian Mountains. Although large-scale forestry operations have been carried out in some parts of the region, the human impacts on trees growing close to the tree line are limited (Gunnarson et al., 2012). Due to the short and cool summers, snags can be preserved for more than 1000 years on the ground (Linderholm et al., 2014) and the subfossil wood can be preserved for hundreds to thousands of years in the sediments of small mountain lakes (Gunnarson, 2008).

\subsection{Description of the tree-ring data}

The reconstruction consists of Scots pine tree-ring samples, collected from seven forest sites in the central Scandinavian Mountains and one historical building in east of the mountains. Figure 1 shows the locations of the sampling sites. All the sites except for the historical building are located within $20 \mathrm{~km}$ of each other, covering an altitudinal extent of $200 \mathrm{~m}$, with slightly different moisture-environments ranging from relatively well-drained soils to wetter lakeshore conditions. Ninety-nine samples from living and dead trees were collected from Mount Furuberget at an elevation of ca. 650 ma.s.l. from a forest with limited stand competition. Thirty-five of the 99 samples were previously used in G11. The site has a thick vegetation layer with woody dwarf shrubs and mosses. Forty samples, mainly from snags, were collected at Mount Håckervalen, elevations ranging from 650 ma.s.l. (the present-day tree line in the area) up to 800 ma.s.l. (Linderholm et al., 2014). Thirty-two samples from subfossil wood were collected at the mountain lakes of Lilla-Rörtjärnen, Östra Helgtjärnen and Jens-Perstjärnen, at 560, 646 and $700 \mathrm{~m}$ a.s.1., respectively (Gunnarson, 2008). The historical samples from Bodsjö, which made up the older part of G11, were downloaded from the International TreeRing Data Bank (ITRDB). The MXD data for the historical samples were obtained using DENDRO2003 X-ray instrumentation from Walesch Electronic (www.walesch.ch). Table 1 provides a full description of the sampling sites and the tree-ring data. Figure 2 shows the sample replication in each site.

The new MXD samples were measured at the tree-ring laboratory of Stockholm University using the ITRAX wood 

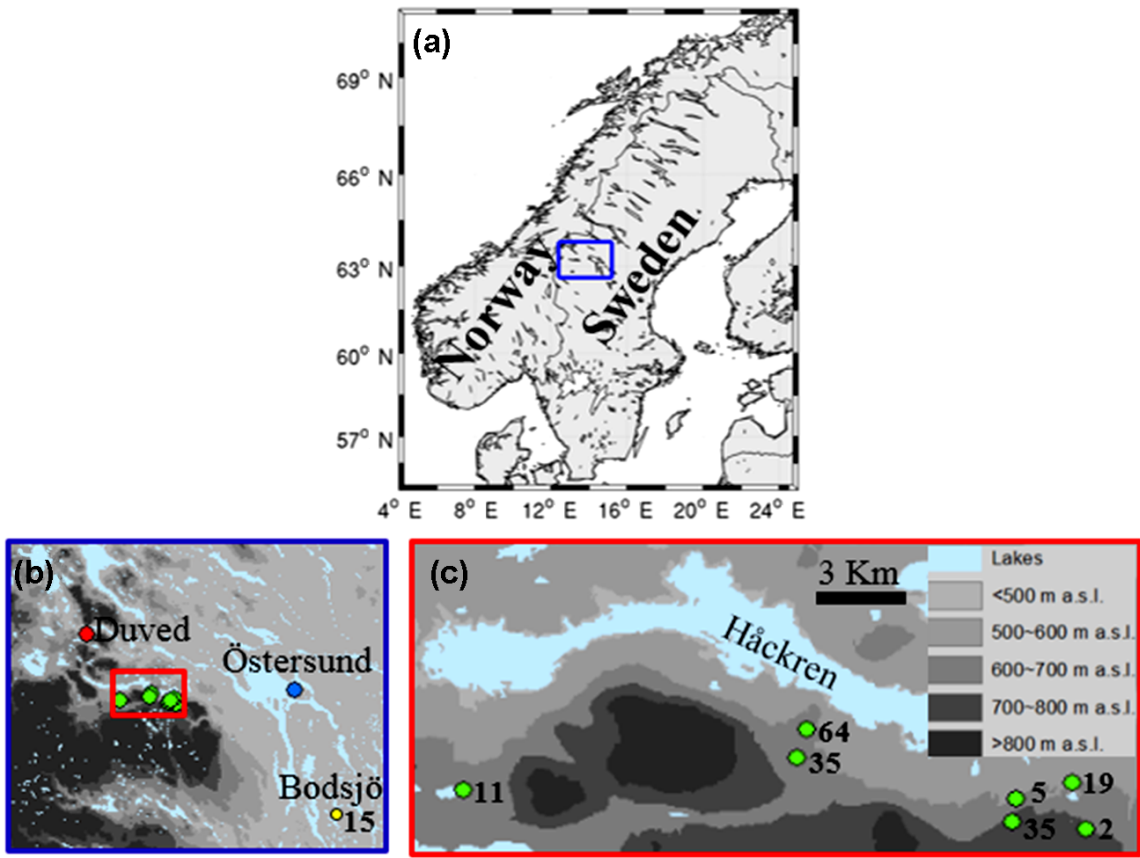

Figure 1. Map showing the locations of (a) the study area and (b) the sites of the mountain Scots pines (green dots), historical building (yellow dot) samples used in this study, and the meteorological stations Duved (red dot) and Östersund (blue dot). (c) shows the topography of the mountain Scots pines. Numbers in (b) and (c) indicate the number of samples collected from each site.

Table 1. Summary of the tree-ring MXD data.

\begin{tabular}{lrrrrrrrr}
\hline Sampling site & Elev & TS & NS & MSL & AMXD & MS & AC1 & M-adj $\left(\mathrm{g} \mathrm{cm}^{-3}\right)$ \\
\hline Furuberget-north & 650 & $873-1112$ & 3 & 156 & 0.74 & 0.118 & 0.556 & 0 \\
& & $1189-2005$ & 61 & 197 & 0.69 & 0.124 & 0.599 & 0 \\
Furuberget-south samples from the G11 study & 650 & $1497-2008$ & 35 & 193 & 0.64 & 0.133 & 0.457 & 0 \\
Håckervalen- south & 750 & $783-1265$ & 30 & 130 & 0.66 & 0.125 & 0.415 & 0.112 \\
& & $1276-1520$ & 5 & 128 & 0.67 & 0.109 & 0.532 & 0.112 \\
Håckervalen- north & 650 & $1778-2011$ & 5 & 213 & 0.71 & 0.165 & 0.314 & 0 \\
Lilla-Rörtjärnen* & 560 & $952-1182$ & 13 & 90 & 0.67 & 0.122 & 0.572 & 0.085 \\
& & $1290-1686$ & 5 & 198 & 0.66 & 0.111 & 0.676 & 0.085 \\
& & $1750-1861$ & 1 & 112 & - & - & - & 0.085 \\
& 646 & $929-1093$ & 6 & 121 & 0.62 & 0.124 & 0.715 & -0.079 \\
Östra Helgtjärnen* & & $1119-1333$ & 3 & 104 & 0.72 & 0.122 & 0.625 & -0.079 \\
& & $1446-1568$ & 2 & 110 & 0.76 & 0.106 & 0.676 & -0.079 \\
& 700 & $1196-1382$ & 2 & 153 & 0.62 & 0.133 & 0.753 & 0.058 \\
Jens Perstjärnen* & 377 & $1107-1291$ & 15 & 158 & 0.84 & 0.082 & 0.676 & -0.112 \\
Bodsjö (historical buildings in Jämtland, & & & & & & & & \\
Sweden) samples from the G11 study & & & & & & & \\
\hline
\end{tabular}

Elev: sampling elevation (ma.s.l.); TS: time span (years CE); NS: number of samples; MSL: mean segment length (year); AMXD: average MXD (g cm ${ }^{-3}$ ); MS: mean sensitivity; AC1: first-order autocorrelation; M-adj: the adjusted values that added to each sample of the corresponding site; * indicates data from subfossil wood collected from lakes. Some of the "mean tree ages" are less than 100 years, because the MXD measurement is only a part of a tree-ring width series, which is much longer. The temporal restriction of these samples is due to some parts of the samples being too rotten for MXD to be measured. MXD data from Furuberget-north, Håckervalen-south, Håckervalen-north, Lilla-Rörtjärnen, Östra Helgtjärnen and Jens Perstjärnen was not included in G11. MXD data from the historical building was downloaded from the International Tree-Ring Data Bank (ITRDB), and was previously used in G11. 
scanner from Cox Analytical Systems (http://www.coxsys. se). Thin laths $(1.20 \mathrm{~mm}$ thick) were cut from each sample using a twin-bladed circular saw, and subsequently put in a Soxhlet apparatus with pure alcohol to remove resins and other compounds. After being processed in the Soxhlet for at least $24 \mathrm{~h}$, the laths were acclimatised in a room with controlled temperature $\left(20^{\circ} \mathrm{C}\right)$ and humidity $(50 \%)$ that yielded ca. $12 \%$ moisture content in the wood, and then mounted in a sample holder. The samples were exposed to a narrow, high-energy, X-ray beam. The chrome tube in the ITRAX was tuned to $30 \mathrm{kV}$ and $50 \mathrm{~mA}$, with $75 \mathrm{~ms}$ step-time. The opening time of the sensor slit was set to $20 \mu \mathrm{m}$ at each step. From the sensor, a 16-bit, greyscale, digital image with a resolution of $1270 \mathrm{dpi}$ was produced. The grey levels of the image were calibrated to values of wood density using a cellulose acetate calibration wedge provided by Walesch Electronics. The MXD data were obtained using the image processing software WinDENDRO.

Zhang et al. (2015) found that MXD data covering the same time period but originating from different elevations/sites can have systematic differences in terms of mean values. The older snag samples in this study were found at progressively higher elevations, as well as contrasting growth environments. If the differences in MXD values caused by elevation and local moisture conditions were not accounted for, it could seriously bias the average chronology, both in terms of the annual to decadal variability and longer-term trends. Therefore, we adjusted the mean MXD values from trees growing at different elevations as well as the subfossil samples (representing a wetter growth environment than the treeline trees) to have the same mean during a common period. Following the protocol proposed by Zhang et al. (2015), we used the mean MXD values of the samples from Furubergetnorth for the period $1300-1550 \mathrm{CE}$ as the reference to correct the in situ data (see Table 1 for adjustment values for each site). The Furuberget-north data were chosen as reference because it had the highest sample replication and widest temporal coverage. The samples from Furuberget-south and Håckervalen-north were not adjusted, because both sample groups were collected from sites where growing conditions (open forests on relatively well-drained soils) and elevations were similar to the reference samples. The mean MXD values of the corrected in situ data and the data from Furubergetnorth for the period 1107-1921 were subsequently used as the reference to correct the historical building data from Bodsjö.

The time-spans of the adjusted and reference samples are shown in Fig. A1 in the Appendix. Some of the samples do not fully cover the common periods, so only the part of a sample overlapping with the common periods was used to compare with reference mean values when calculating the adjusted value for each sub-site. In the previous study (Zhang et al., 2015) we found that the differences in mean absolute MXD values among the sites of different elevations in a given period were larger than among the sites of simi- lar elevation between MCA and LIA. Therefore, we argue that the slight-mismatch of the time-spans within the common periods among the sub-sites should not bias the meanadjustment. Figure A2 shows the age-aligned average curves for the samples partly or fully covering the reference periods before and after the mean-adjustment, along with the average curve of the reference samples. The average curves were smoothed using spline functions. The smoothed average curves show that MXD values generally decrease with tree age. The average curve of the adjusted samples displays the same mean MXD level as the average curve of the reference samples.

In a tree-ring MXD series, MXD values change with age. Therefore, this should be taken into consideration when applying the mean-adjustment methodology (Zhang et al., 2015), and each group of samples should have a homogeneous age distribution in the selected reference period, as well as the adjustment periods. Mean age statistics of the reference and mean-adjusted samples are shown in Table A1 in the Appendix. During the common period 1300-1550, the mean age of samples at the reference site (Furubergetnorth) is 105 years, Håckervalen-south: 101 years, Ö Helgtjärnen: 90 years, Lilla-Rörtjärnen: 86 years, Jens Perstjärnen: 153 years. During the common period 1107-1291, the reference site mean age is 70 years and for Bodsjö it is 79 years. This shows that the mean ages of most of the sites at these common periods do not deviate substantially from each other (the mean ages represent mature trees, not juvenile or old-age trees which can be said to deviate in mean values just because of age). From Fig. A2a, we can see that the difference of the MXD values at this age range is much smaller than the difference caused by the elevation and/or local-environment (see also the adjusted values in Table 1). Therefore, we argue that mean-adjustment should not be biased by tree age in these sample materials.

\subsection{Standardisation methods}

To obtain high-quality climate information from tree-ring data, it is necessary to remove as much non-climatic "noise" as possible before building a chronology from the individual tree-ring series (Fritts, 1976). The non-climatological growth effect is usually represented with a least-squares-fitted negative exponential function, polynomial or spline (Fritts, 1976; Cook and Peters, 1981). This is subsequently removed from corresponding values of the measurements, either by subtraction or division, in a process termed standardisation. This approach is widely used, but it severely limits the preservation of low-frequency variability in long chronologies (based on several generations of trees), because the mean values of all the tree-ring series are adjusted to the same level after standardisation. The limitation in preserving low-frequency variability is referred to as the "segment length curse" (Cook et al., 1995; Briffa et al., 1996). 


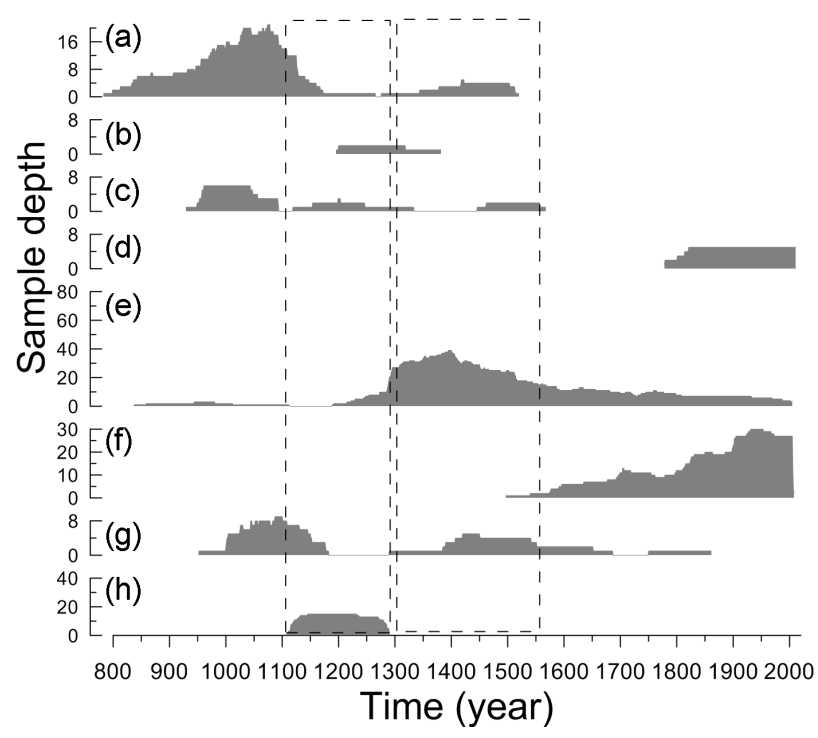

Figure 2. Sample replication through time at (a) Håckervalensouth, (b) Jens Perstjärnen, (c) Östra Helgtjärnen, (d) Håckervalennorth, (e) Furuberget-north, (f) Furuberget-south (G11), (g) LillaRörtjärnen and (h) Bodsjö. The dashed lines mark the two reference periods for mean adjustment (see main text).

The limitation can be overcome by quantifying the nonclimatological growth expression for an entire population as an average of the growth of all samples aligned by cambial age, which then can be represented by a single mathematical function. Subsequently this function is removed from each individual tree-ring measurement, an approach called Regional Curve Standardisation (RCS, Briffa et al., 1992). By using one single function for all tree-ring series, less unwanted mid-frequency variability is removed in an attempt to preserve the low-frequency (> segment length) variability (Melvin, 2004), along with possible trend distortion as described in Melvin and Briffa (2008). Melvin and Briffa (2014a, b) showed that multi-curve RCS could, however, efficiently remove these biases. Alternatively, nonclimatological effects in tree-ring data can be quantified with an individual signal-free (SF) approach, described in Melvin and Briffa (2008), but this approach is also limited in the lower-most frequencies (Björklund et al., 2013).

However, using the SF individual fitting approach and at the same time letting the derived functions have a similar mean as the respective cambial age segment of the regional curve (RC) before subtraction into indices, stand competition etc. can also be addressed without losing the long timescale component (Björklund et al., 2013). This method is a hybrid of the RCS and individual SF standardisation, and was termed RSFi. In this study, we produced MXD chronologies using two standardisation methods: two-curve signalfree RCS (fitted by age-dependent splines) and RSFi (fitted by age-dependent splines), where the RSFi chronology was used for the new reconstruction. In both methods, resid-

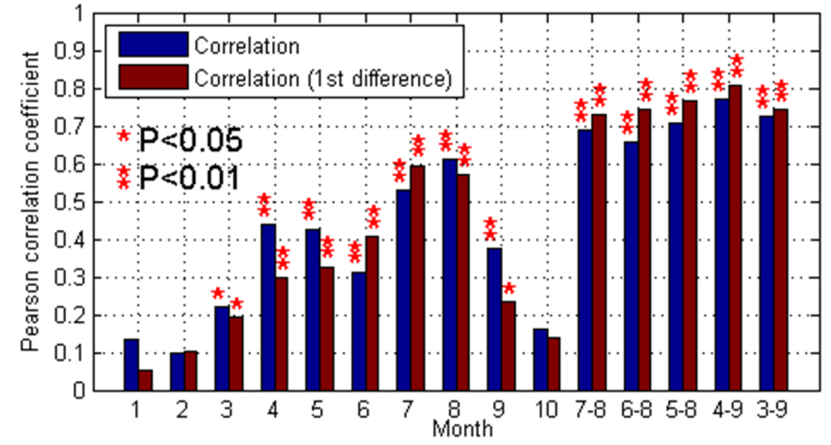

Figure 3. The correlations between the mean-adjusted MXD chronology, standardised with the RSFi method, and observed monthly mean temperatures from Duved meteorological station over the period 1890-2011. The correlations are given from January to October of the present year and July-August, JuneAugust, May-August, April-September (warm season) and MarchSeptember means.

uals between raw data and fitted functions were calculated, and subsequently averaged to produce the final chronology. The standardisations were performed using the software RCSsigFree (Cook et al., 2014) and CRUST (Melvin and Briffa, 2014a, b). The expressed population signal (EPS) criterion was used to evaluate the robustness of the chronology. An EPS value represents the percentage of the variance in the hypothetical population signal in the region that is accounted for by the chronology, where EPS values greater than 0.85 are generally regarded as sufficient (Wigley et al., 1984). Here the EPS values were calculated in a 50-year window with a 1-year lag.

\subsection{Instrumental data}

Monthly temperature data from the closest meteorological station, Duved ( $400 \mathrm{ma}$ a.s.1., $63.38^{\circ} \mathrm{N}, 12.93^{\circ} \mathrm{E}$ ), was used to assess the temperature signal reflected by the chronology. Since the data from this station only cover the period 19111979 , the data were extended back to $1890 \mathrm{CE}$ and up to $2011 \mathrm{CE}$ using linear regression on monthly temperature data from an adjacent station: Östersund (376 ma.s.1., $63.20^{\circ} \mathrm{N}$, $\left.14.49^{\circ} \mathrm{E}\right)$. Data from Östersund explained on average $91.5 \%$ of the inter-annual variance of Duved monthly temperatures (based on the overlapping period 1911-1979). The temperature data from Östersund came from two sources: the Nordklim data set (1890-2001) (Tuomenvirta et al., 2001) and Swedish Meteorological and Hydrological Institute (SMHI, 2001-2011 CE). The locations of Duved and Östersund stations are shown in Fig. 1.

\subsection{Climate signal and reconstruction technique}

We calculated correlations between the new MXD chronology and instrumental monthly mean temperatures from 
Duved over the period 1890-2011 CE. Figure 3 shows that these are significantly correlated $(p<0.01)$ for all individual months from April to September, and the correlation with mean April-September temperature is 0.77 . The correlation is $0.81(p<0.01)$ if only inter-annual variability were considered. Same results were obtained $(0.77, p<0.01)$ when correlating the MXD chronology with mean AprilSeptember temperature from the closest grid in the CRU TS3.23 $0.5^{\circ} \times 0.5^{\circ}$ data set (Harris et al., 2014) over the period 1901-2011. A transfer model was developed using simple linear regression, where the April-September temperature anomalies (deviations from the 1961-1990 mean) were set as the predictand and the MXD data of the current year $(t)$, as the predictor. The temporal stability of the model was tested with a split sample calibration-verification procedure (Gordon, 1982), where the period of MXD and meteorological data overlap (1890-2011) was divided into two periods of roughly equal length (1890-1950 and 1951-2011 CE, respectively). Calibration and verification statistics were then calculated for the first and second half of the period, respectively. The calibration and verification periods were then exchanged and the process repeated. The validation was performed using the explained variance $\left(R^{2}\right)$, reduction of error (RE), coefficient of efficiency (CE) statistics (National Research Council, 2006).

The final model was calibrated over the full 1890-2011 period. The uncertainty of the reconstruction was estimated from two sources: chronology characteristics (temporal variations in replication) and the calibration statistics according to the methods of Yang et al. (2014). The uncertainty in the chronology was estimated by \pm 2 times the standard error (i.e. the standard deviation of all MXD index values in each year divided by the square root of the sample replication). The calibration uncertainty was estimated from the standard deviation of the reconstruction residuals (i.e. the difference between observed and reconstructed temperatures). The error of the reconstruction was estimated by the square root of the sum of the squared chronology error and the squared calibration uncertainty. The uncertainty of the reconstruction was then estimated by \pm 2 times of the reconstruction error.

\section{Result and discussion}

\subsection{The new reconstruction and reconstruction statistics}

The calibration and verification statistics are summarised in Table 2. The RE and CE statistics are well above zero, and thus pass the validation tests (National Research Council, 2006). Figure 4a shows a linear relationship between the MXD data and Duved April-September mean temperatures over the period 1890-2011. The reconstructed and observed warm-season temperatures show good agreement on interannual and multi-decadal timescales (Fig. 4b). The reconstruction has a slightly smaller spatial representation than observed station data when compared to gridded tempera-
Table 2. The calibration and verification statistics of the warmseason temperature reconstruction.

\begin{tabular}{lrrr}
\hline \multicolumn{4}{c}{ MXD RSFi chronology } \\
\hline Calibration period & $1890-1950$ & $1951-2011$ & $1890-2011$ \\
Correlation coefficient, $R$ & $0.82^{*}$ & $0.68^{*}$ & $0.77^{*}$ \\
Explained variance, $R^{2}$ & 0.67 & 0.47 & 0.59 \\
No. of observations & 61 & 61 & 122 \\
Verification period & $1951-2011$ & $1890-1950$ & - \\
Explained variance, $R^{2}$ & 0.47 & 0.67 & - \\
Reduction of error (RE) & 0.56 & 0.72 & - \\
Coefficient of efficiency (CE) & 0.45 & 0.66 & - \\
Slope & - & - & 0.57 \\
Intercept & - & - & -0.145 \\
\hline
\end{tabular}

* correlation is significant at the $p<0.01$ level.

(a)

(b)
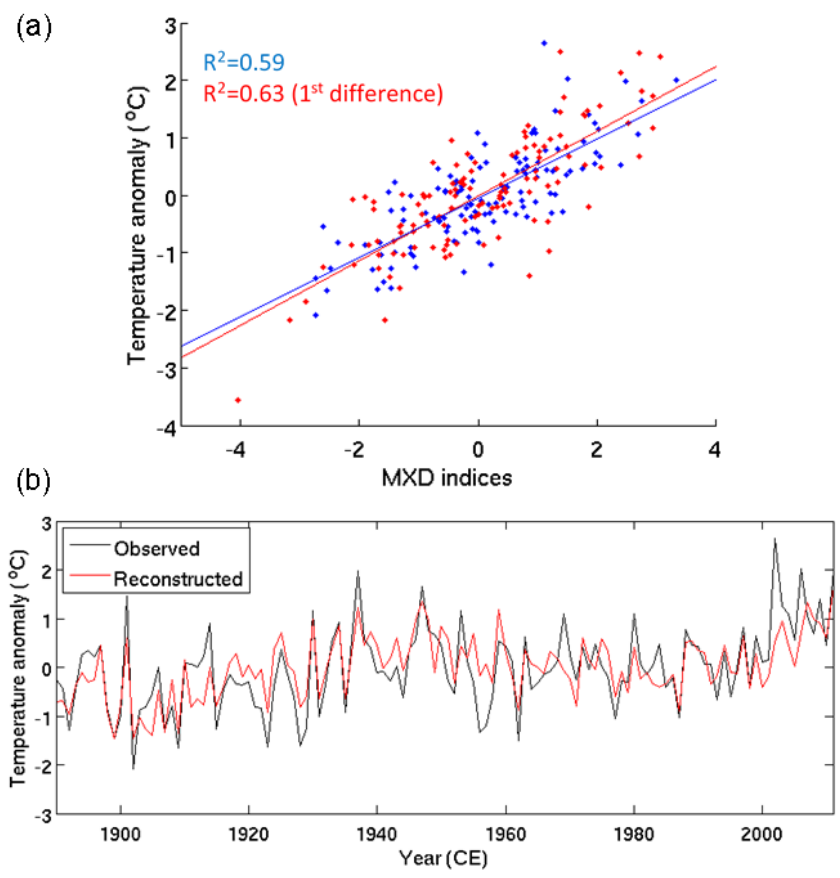

Figure 4. (a) Scatter plot of the MXD indices versus observed warm-season temperature anomalies (relative to 1961-1990 mean) from Duved (blue), and their respective 1st difference components (red), and (b) a comparison of reconstructed warm-season temperatures (red) and observed Duved warm-season temperatures (black) over the period 1890-2011.

tures (Fig. 5). However, the new reconstruction still represents much of central Fennoscandia, and has a much more southerly expression than the northern MXD chronologies mentioned in the introduction (Melvin et al., 2013; Esper et al., 2012; McCarroll et al., 2013), and a more western expression than Helama et al. (2014). 

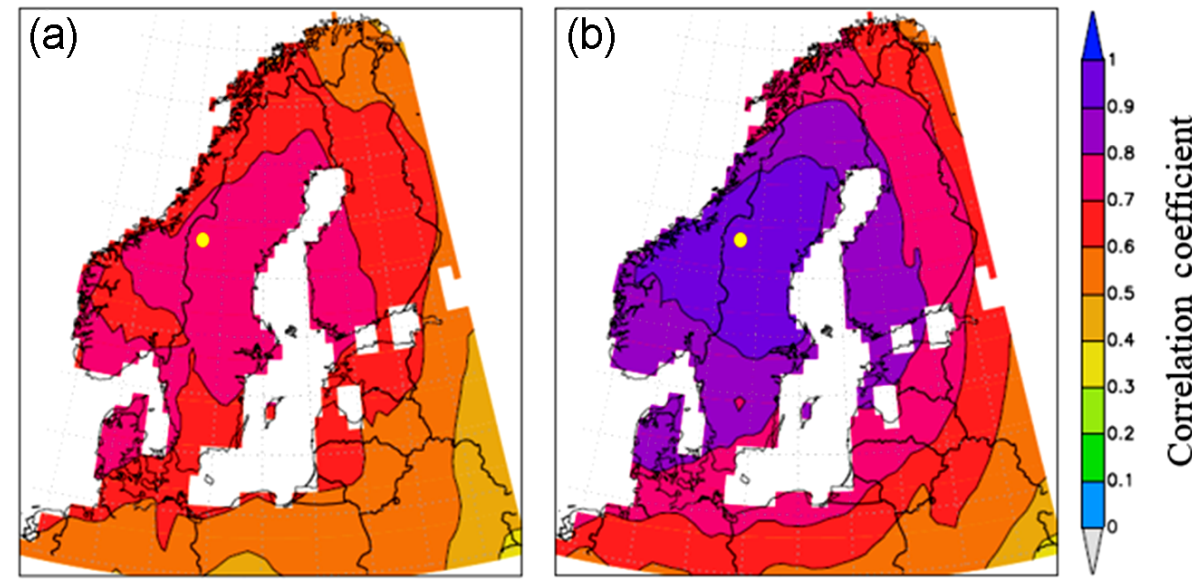

Figure 5. Field correlations between gridded warm-season temperature from the CRU TS3.23 $0.5^{\circ} \times 0.5^{\circ}$ data set (Harris et al., 2014) during the period 1901-2011 CE and (a) reconstructed warm-season temperatures (this study), and (b) observed Duved warm-season temperatures. The yellow dots mark the approximate locations of the sampling sites. The field correlation maps were made using the "KNMI climate explorer" (Royal Netherlands Meteorological Institute; http://climexp.knmi.nl; van Oldenborgh et al., 2009).

\subsection{Central Scandinavian warm-season temperature evolution}

Figure 6a shows that the differences between the meanadjusted and the non-adjusted MXD chronologies mainly occur before $1300 \mathrm{CE}$. The mean-adjusted chronology shows lower values between 1150 and 1300 and higher values between 850 and 1100, compared to the non-adjusted chronology. Clearly, not using the mean adjustment would have large impacts on the interpretation of the temperature evolution during the last millennium. If possible, this principle should always be utilised when data from slightly different growth environments, with sufficient overlap, are composited before standardisation. Figure $6 \mathrm{c}$ shows that the EPS values are above 0.85 during most of the last millennium, testifying to the robustness of the chronology in representing the hypothetical population signal. However, there is a dip in EPS values during the period 1150-1200 which reduces the validity of the reconstruction in this period. EPS values are influenced by two factors: number of samples and inter-series correlations (Wigley et al., 1984). Obviously, the dip in EPS values in this case should be attributed to relatively weak inter-series correlation over that time period compared to other time periods during the last millennium. It should be noted that the chronology during this period consists of both tree-line and low-elevation (historical) samples. However, during most of the last millennium, the variability of the tree-ring samples from the two sources (tree-line and historical) do not show obvious differences at inter-annual (not show) to centennial (Fig. 7) timescales.

When comparing the MXD chronologies based on the RSFi and the two-curve signal-free RCS standardisation (Fig. 6b), the two chronologies are very similar at multidecadal timescale. Because of this, and the assumption that the former methodology has a greater chance at removing mid-frequency noise (Björklund, 2014), we chose the RSFi method for our reconstruction. Fig. 6d shows the reconstructed warm-season temperatures in central Scandinavia, henceforth referred to as C-Scan, during the past 1150 years. C-Scan displays a cooling trend over the period 850-1900, followed by a sharp temperature increase in the 20th century. C-Scan suggests a moderate MCA warm-peak during ca. 1000 to $1100 \mathrm{CE}$ in central Scandinavia. Our reconstruction indicates that the warm-season warmth during MCA is not so pronounced in central Scandinavia, which adds further detail to our knowledge about the spatial pattern of surface air temperature on the regional scale. The new reconstruction is therefore very important for future spatial temperature reconstructions such as Luterbacher et al. (2016).

$\mathrm{C}-\mathrm{Scan}$ indicates that, in this region, the cold period known as the Little Ice Age (LIA, Grove, 2001) spans the mid-16th century to the end of the 19th century, where the coldest 100year period is found in the late 18th to late 19th century. Both the coldest 10- and 30-year periods are found around 1600 CE. The warmest 10-, 30- and 100-year periods during the last millennium are all found in the 20th century. Comparing the MCA to the 20th century, the warmest 10-, 30- and 100 -year in the 20th century are $0.3,0.1$ and $0.03{ }^{\circ} \mathrm{C}$ warmer in the 20th century than those in the 10th and 13th centuries respectively. However, the reconstruction based on the twocurve signal-free RCS standardised chronology indicates that the coldest 100-year period appears in the 18th century during the last millennium.

Figure 7 shows a comparison between C-Scan and G11. The two reconstructions show coherent variability at multidecadal to centennial timescales during the period 1300 2000. However, the 12th century is portrayed as much warmer in G11 than in C-Scan, and we largely attribute this 


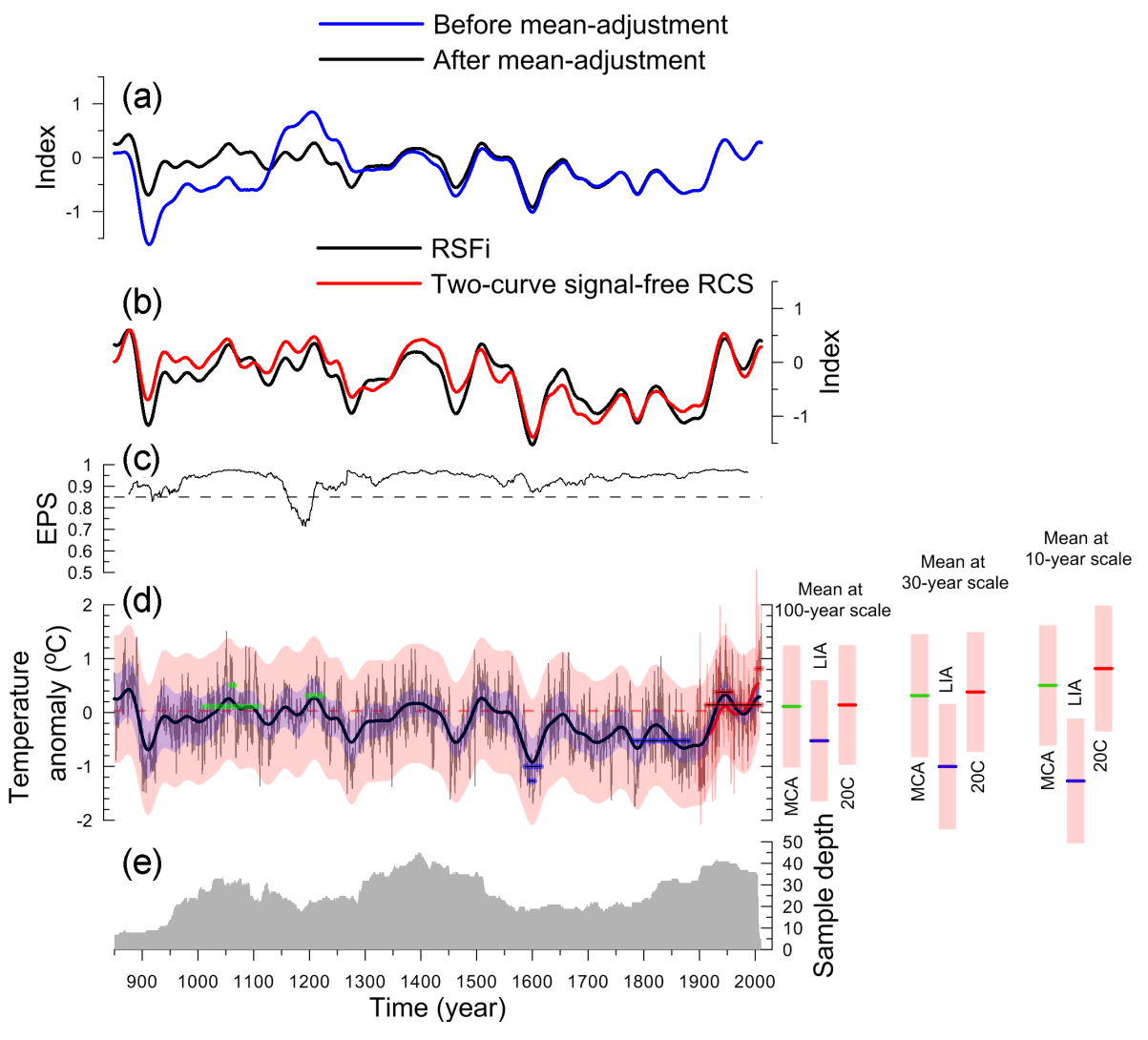

Figure 6. Characteristics of the central Scandinavian MXD chronology and the resulting warm-season temperature reconstruction: (a) The MXD chronologies based on samples without mean-adjustment (blue) and after mean-adjustment (black). (b) Comparison of the multidecadal (after 51-year Gaussian filtering) variability of the MXD chronologies standardised by the two-curve signal-free RCS standardisation method (smoothed by age-dependent spline, the red curve) and the RSFi standardisation method (fitted by age-dependent spline, the black curve). (c) Expressed Population Signal (EPS) through time of the chronology. The dashed line shows the 0.85 threshold. (d) Reconstructed annual (grey) and 51-year Gaussian filtered (bold black) warm-season temperature variability in central Scandinavia over the period 850-2011. Also indicated is the chronology uncertainty (purple shading) and the total uncertainty of the reconstruction (pink shading. This includes chronology uncertainty and reconstruction uncertainty) expressed as \pm 2 times the standard error. Observed warm-season temperatures are shown by the thin red (annual) and the bold red (after 51-year Gaussian filtering) curves, with the red dashed line indicating the 1961-1990 mean. The short lines to the right of panel (d) mark the mean temperature levels of the warmest 100, 30 and 10 years in MCA (10th-13th century, Grove and Switsur, 1994) (green) and 20th century (red), and the coldest 100, 30 and 10 years in the LIA (14th-19th century, Grove, 2001) (blue). The time spans are marked on the corresponding positions on the temperature curve. The coloured short lines with thin solid black line in the centre mark the time spans of the warmest and coldest 100, 30 and 10 years during the past 1200 years. (e) The grey shading indicates the sample depth of the MXD chronology.

discrepancy to the omission of adjusting the mean values of the samples from different elevations in G11. However, if this feature is disregarded, the comparison between C-Scan and G11 actually shows that the historical building samples perform quite well in representing the temperature variability at multi-decadal to centennial timescales. Considering the performance of the historical samples and the low replication of the newly collected samples around $1200 \mathrm{CE}$, we argue that it is better to use the historical samples when sample depth is low, than not to use them at all. Therefore, we included mean adjusted historical samples for the period 1107-1291 CE in our reconstruction. The EPS values are improved over that time period, but still do not reach the 0.85 threshold.
Compared to G11, the merit of C-Scan is manifested by three aspects: (1) C-Scan covers the whole of MCA and can be used to interpret the temperature evolution during this important phase in our temperature history. (2) The application of the mean-adjustment method. Our results suggest that also the historical-building samples, used in G11, should be separately mean-adjusted according to their origin and mean values, and not be treated as a homogenous data set. (3) CScan is $92 \%$ based on the samples collected from a relatively small mountain area, close to the local tree line, compared to G11, which is $73 \%$ based historical samples. Even though the historical samples seemingly perform in a similar way to the tree-line samples, trees at the limit of their distribution 


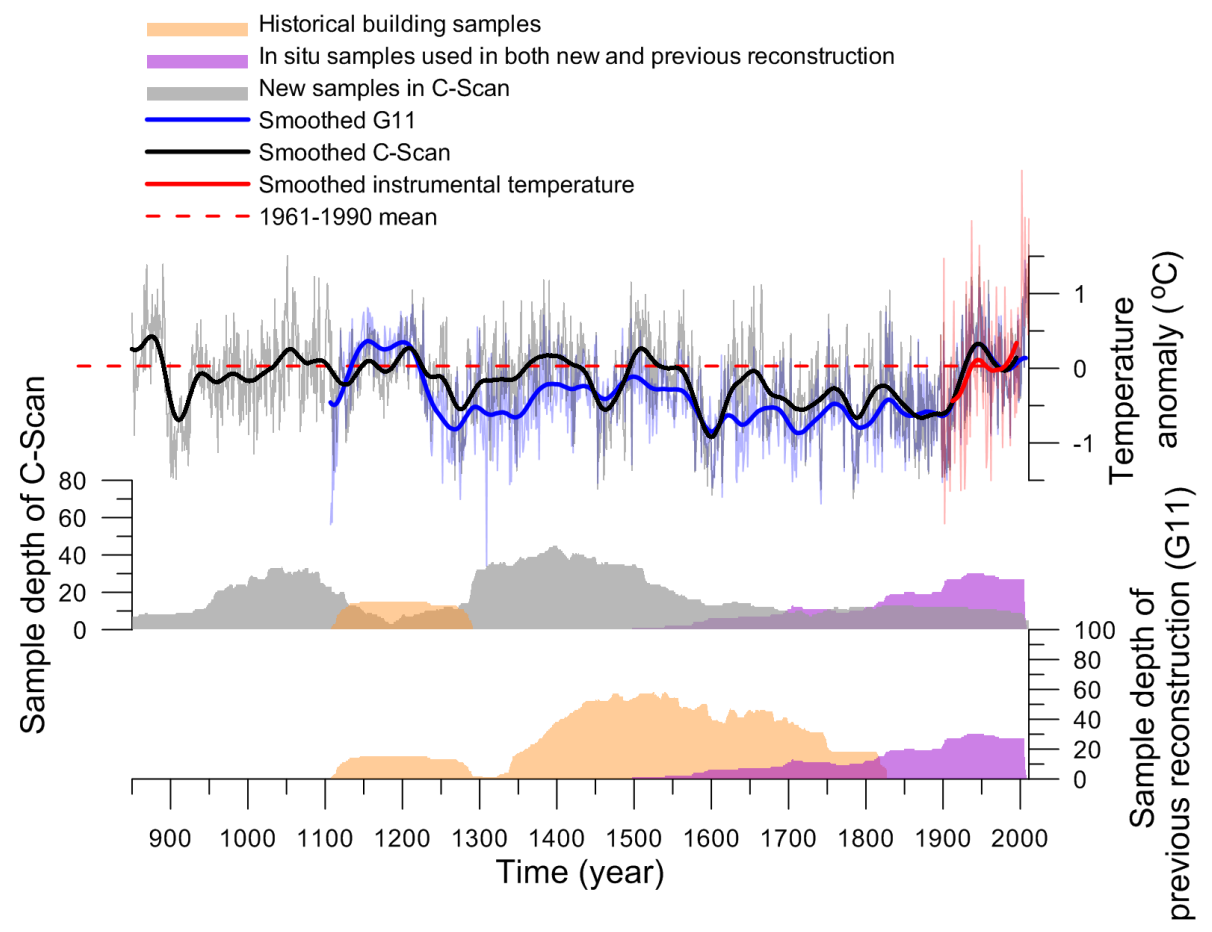

Figure 7. A comparison between C-Scan (thin grey curve) and G11 (thin blue curve, Gunnarson et al., 2011). Bold black and blue curves show the variability after 51-year Gaussian filtering. The sample depths of different origins used in the two reconstructions are marked by the orange, grey and purple (C-Scan) and orange and purple (G11) shadings, respectively. The red curves indicate the observed year-toyear temperature variability (thin line) and its 51-year Gaussian filtered variability (thick line). The dashed red curve shows the observed 1961-1990 mean warm-season temperature.

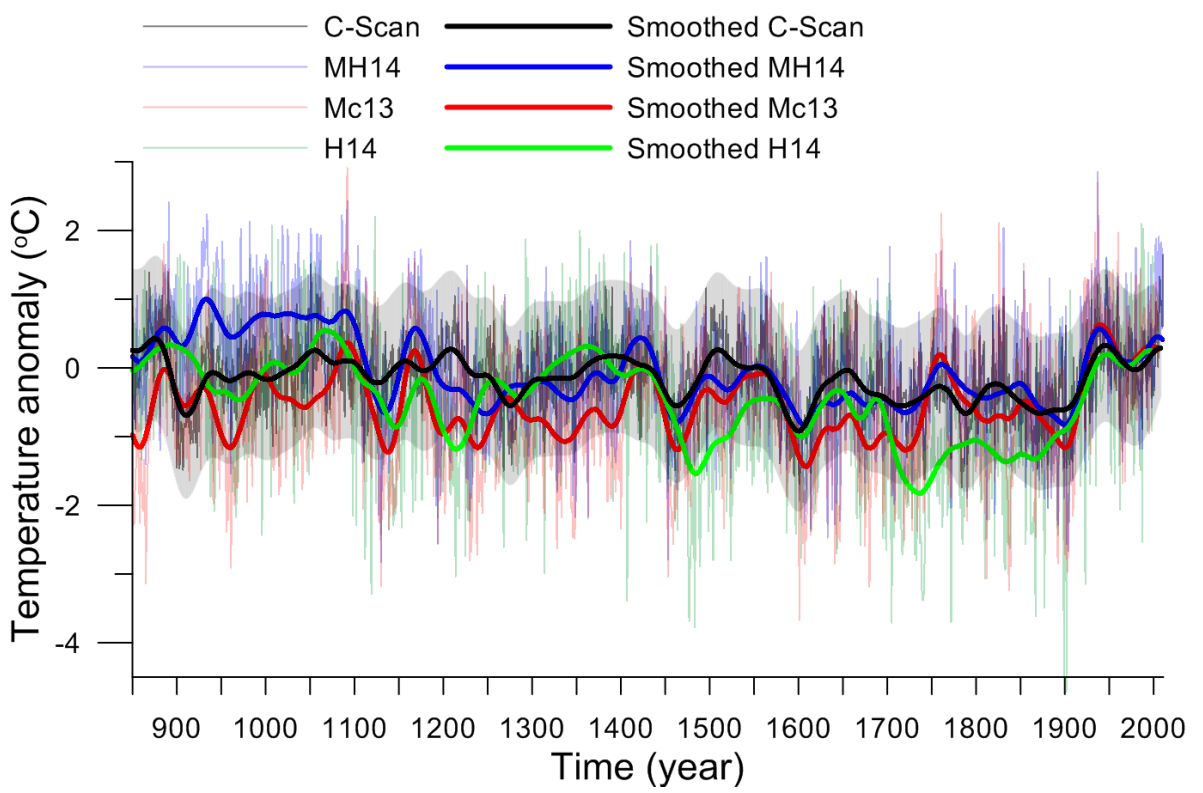

Figure 8. Comparison of temperature anomalies (from 1961-1990 period) inferred by four temperature reconstructions covering the whole last millennium: C-Scan (April-September, this study, black), MH14 (June-July, MXD, blue, Matskovsky and Helama, 2014), Mc13 (JuneAugust, multi-proxy, red, McCarroll et al., 2013) and H14 (May-September, MXD, green, Helama et al., 2014). Bold curves show the variability after 51-year Gaussian filtering. The black shading indicates the total uncertainty of C-Scan (including chronology uncertainty and reconstruction calibration uncertainty), as expressed as \pm 2 times the standard error. 
should be more sensitive and thus perform better, and are preferred for reconstructions, according to the principle of limiting factors (Fritts, 1976). This is perhaps corroborated by the fact that the new reconstruction displays a larger variance at some periods, such as stronger cooling events around 1450 and $1600 \mathrm{CE}$ than those in G11. This could be interpreted as a more coherent variability (lower noise level) among the newly collected samples than the historical building samples, which is always desirable.

\subsection{Comparing C-Scan with other Fennoscandian summer temperature reconstructions}

Annually resolved summer and warm-season temperature reconstructions covering the entire last millennium, based on MXD data, have almost exclusively focused on northern Fennoscandia (McCarroll et al., 2013, henceforth referred to as Mc13; Esper et al., 2012; Melvin et al., 2013; Matskovsky and Helama, 2014, henceforth referred to as MH14), with the exception of the reconstruction for southern Finland (Helama et al., 2014, henceforth referred to as H14). A general feature of these reconstructions is a cooling trend during the last millennium until the end of the 19th century, consistent with the reduction in high-latitude summer solar insolation related to orbital forcing (Helama et al., 2010; Esper et al., 2012), followed by an abrupt warming trend during the 20th century, related to increasing $\mathrm{CO}_{2}$ concentrations in the atmosphere (Stocker et al., 2013). However, differences among these reconstructions, even those focused on the northernmost part of the region, have been discussed (e.g. Matskovsky and Helama, 2014; Linderholm et al., 2015). In Fig. 8, C-Scan is compared with MH14, Mc13 and H14. $\mathrm{C}$-Scan shows smaller variance than the other three reconstructions, likely because it was calibrated based on a longer time window (i.e. April-September) than the others (MH14: June-July; Mc13: June-August; H14: May-September). The multi-decadal variability of $\mathrm{H} 14$ generally differs from the others, where the pronounced cooling during the LIA stands out. The other segments of the reconstructions agree quite well, although Mc13 generally shows cooler anomalies than MH14 and C-Scan. The largest discrepancy among the reconstructions is found between 900 and $1100 \mathrm{CE}$ (the MCA), where MH14 shows persistent warm anomalies, whereas Mc13 shows cooling and in C-Scan temperatures are only slightly above the long-term average. MCA temperatures in H14 are similar to C-Scan, but slightly higher.

It is possible that the discrepancies among the reconstructions is partly attributed to methodological issues, such as changes in numbers of samples through time in the chronologies, or periods where trees show less coherent growth patterns (e.g. the 1150-1200 period in C-Scan). Such issues can be alleviated through careful selection of the tree-ring data and more coherent standardisation method and parameters (Frank et al., 2010; Björklund, 2014). However, the differences in reconstructed temperatures may also be expressions of sub-regional differences associated with varying atmospheric circulation patterns that influence across Fennoscandia through time. Linderholm et al. (2015) discussed the possibility that changes in the average positions of circulation patterns such as the NAO, related to changes in the polar jet stream configuration, could have an influence on the homogenous summer temperature pattern in Fennoscandia observed today. The influence of the Atlantic Multi-decadal Oscillation can also be of importance, due to the proximity of the study region to the ocean. Furthermore, Irannezhad et al. (2014) found that the trends of observed annual and seasonal surface air temperatures show spatial differences in Finland, and that the warm-season temperatures can be related to different regional-scale circulation patterns such as the East Atlantic, West Russia, Scandinavian and West Pacific patterns in different sub-regions. Thus, it is likely that summer temperature variability in different sub-regions throughout Fennoscandia is controlled by different circulation patterns, and that asymmetric changes in these circulation patterns induce spatial differences in summer temperature evolution. A more detailed study of regional temperature patterns in Fennoscandia, and their associated regional-scale circulation patterns, would be useful to test if the spatial differences of warm-season temperature evolution occur in the past during different climate settings, especially during the MCA, being an important analogue to the present-day warming.

\section{Conclusions}

In this study we updated and extended the MXD data that were previously used to reconstruct central Scandinavian warm-season temperatures. The new reconstruction, C-Scan, now extends back to $850 \mathrm{CE}$, and includes the MCA. Compared to the previous reconstruction, G11, the issue of biases arising from samples from different locations was appropriately addressed and corrected using the mean-adjustment method. C-Scan is largely based on high-quality tree-line samples collected from a smaller area.

C-Scan suggests a moderate MCA warm-peak during ca. 1000 to $1100 \mathrm{CE}$ in central Scandinavia and a LIA lasting from the mid-16th century to the end of the 19th century. During the last millennium, the coldest 10- and 30-year periods occurred around $1600 \mathrm{CE}$ in central Scandinavia. The warmest 10- and 30-year periods were found in the 20th century. C-Scan indicates lower temperatures during the late MCA (ca. 1130-1210 CE) and higher temperatures during the LIA (1610-1850 CE) than G11.

Some differences in multi-decadal to multi-centennial variability between $\mathrm{C}$-Scan and other MXD-based temperature reconstructions from Fennoscandia were found, suggesting regional differences of summer or warm-season temperature evolution, possibly linked to varying influences of atmospheric circulation patterns. However, this needs to be further investigated. 


\section{Data availability}

The new reconstruction, C-Scan, will be uploaded to NOAA and BALPAL, and all the data published in this study will be available for non-commercial scientific purposes. 


\section{Appendix A}

Table A1 and Fig. A1 show the mean age statistics and the time spans of the reference and mean-adjusted samples, respectively. The age-aligned average curves for the samples partly or fully covering the reference periods before and after the mean adjustment and the average curve of the reference samples are shown in Fig. A2.

Table A1. Mean age statistics of the reference and mean-adjusted samples.

\begin{tabular}{clcccc}
\hline Common period & Site & Number of samples & Mean start age & Mean end age & Mean age \\
\hline \multirow{2}{*}{$1300-1550$} & Furuberget-north (reference) & 50 & 33 & 176 & 105 \\
& Håckervalen-south & 5 & 40 & 162 & 101 \\
& Ö Helgtjärnen & 3 & 52 & 127 & 90 \\
& Lilla-Rörtjärnen & 5 & 12 & 160 & 86 \\
& Jens Perstjärnen & 2 & 128 & 178 & 153 \\
\multirow{2}{*}{$1107-1291$} & In situ (reference) & 42 & 51 & 89 & 70 \\
& Bodsjö (historical building) & 15 & 1 & 158 & 79 \\
\hline
\end{tabular}

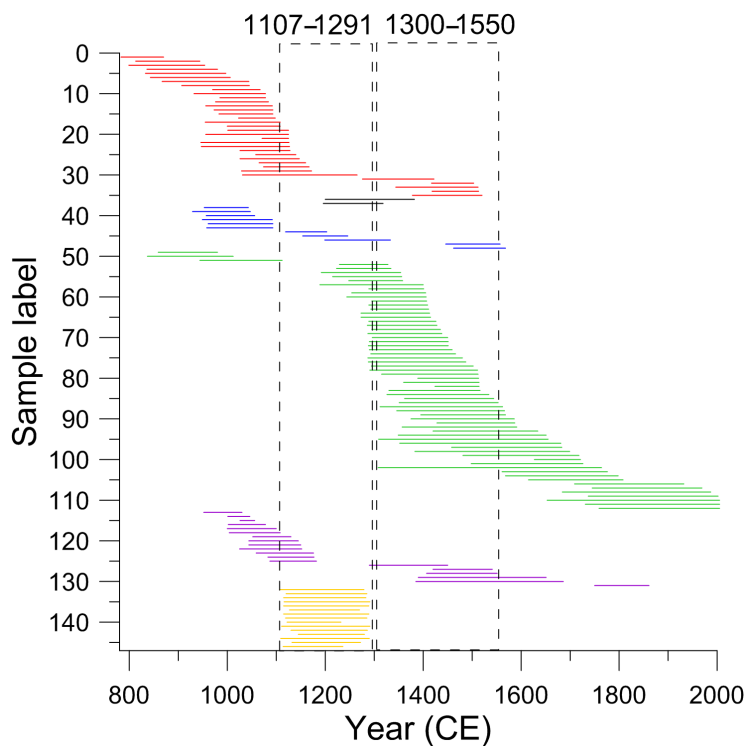

Figure A1. The time spans of the samples from Håckervalensouth (red), Jens Perstjärnen (black), Östra Helgtjärnen (blue), Furuberget-north (green), Lilla-Rörtjärnen (purple) and Bodsjö (yellow). The samples from Furuberget-north which are fully or partly covering the period 1300-1550 are used as references for adjusting the mean values of the samples from Håckervalensouth, Jens Perstjärnen, Östra Helgtjärnen and Lilla-Rörtjärnen. The samples from Furuberget-north and the adjusted samples from Håckervalen-south, Jens Perstjärnen, Östra Helgtjärnen and LillaRörtjärnen which are fully or partly covering the period 1107-1291 are used as references for adjusting the mean values of the samples from Bodsjö. 
(a) Mean-adjustment based on 1300-1550

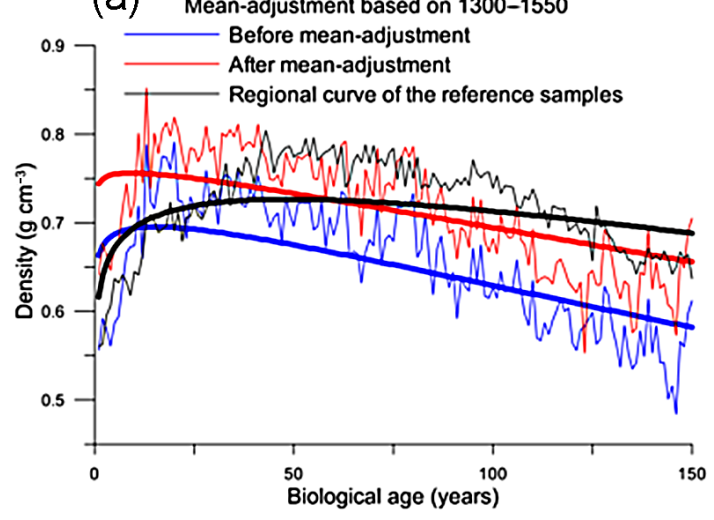

(b) Mean-adjustment based on 1107-1291

Before mean-adjustment

After mean-adjustment

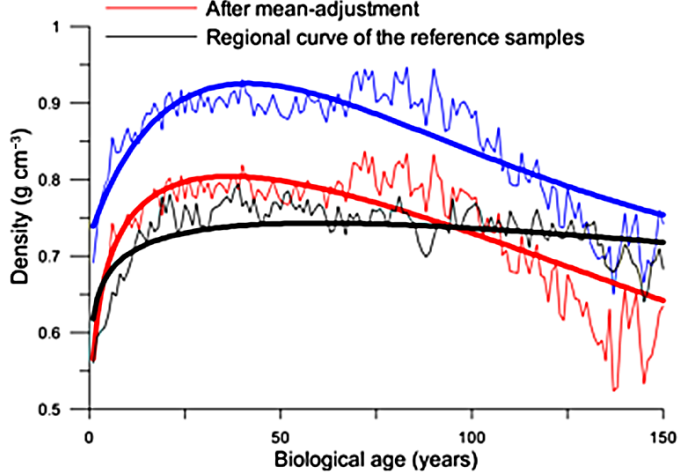

Figure A2. (a) The smoothed (bold) and unsmoothed (thin) average growth curves of the referenced samples (from Furuberget-north, black) and the samples (from Håckervalen-south, Lilla-Rörtjärnen, Östra Helgtjärnen and Jens Perstjärnen) before (blue) and after (red) meanadjustment in the common period (1300-1550), (b) the same as (a) but for the mean-adjustment of the historical building samples over the period 1107-1291. 
Acknowledgements. We acknowledge the County Administrative Boards of Jämtland for giving permission to conduct dendrochronological sampling, and Mauricio Fuentes, Petter Stridbeck, Riikka Salo, Emad Farahat, Kristina Seftigen, Eva Rocha and Peter Seftigen for their help in the field. We also thank Laura McGlynn and Håkan Grudd for assistance in the MXD measurements and Andrea Seim for helping out with GIS and correcting the manuscript. We thank the editor and reviewers for their great suggestions, and David Rayner for correcting the English. This work was supported by Grants from the two Swedish research councils (Vetenskapsrådet and Formas, Grants to Hans Linderholm) and the Royal Swedish Academy of Sciences (Kungl. Vetenskapsakademien) (grant to Peng Zhang). This research contributes to the strategic research areas Modelling the Regional and Global Earth system (MERGE), and Biodiversity and Ecosystem services in a Changing Climate (BECC) and to the PAGES2K initiative. This is contribution no. 33 from the Sino-Swedish Centre for Tree-Ring Research (SISTRR).

Edited by: E. Zorita

\section{References}

Bindoff, N. L., Stott, P. A., AchutaRao, K. M., Allen, M. R., Gillett, N., Gutzler, D., Hansingo, K., Hegerl, G., Hu, Y., Jain, S., Mokhov, I. I., Overland, J., Perlwitz, J., Sebbari, R., and Zhang, X.: Detection and Attribution of Climate Change: from Global to Regional, in: Climate Change 2013: The Physical Science Basis, Contribution of Working Group I to the Fifth Assessment Report of the Intergovernmental Panel on Climate Change edited by: Stocker, T. F., Qin, D., Plattner, G. K., Tignor, M., Allen, S. K., Boschung, J., Nauels, A., Xia, Y., Bex, V., and Midgley, P. M., Cambridge University Press, Cambridge, United Kingdom and New York, NY, USA, 2013.

Björklund, J. A.: Tree-rings and climate: standardization, proxy development, and Scandinavian summer temperature history, $\mathrm{PhD}$ thesis, Department of Earth Sciences, University of Gothenburg, Sweden, 2014.

Björklund, J. A., Gunnarson, B. E., Krusic, P. J., Grudd, H., Josefsson, T., Östlund, L., and Linderholm, H. W.: Advances towards improved low-frequency tree-ring reconstructions, using an updated Pinus sylvestris L. MXD network from the Scandinavian Mountains, Theor. Appl. Climatol., 113, 697-710, 2013.

Björklund, J. A., Gunnarson, B. E., Seftigen, K., Esper, J., and Linderholm, H. W.: Blue intensity and density from northern Fennoscandian tree rings, exploring the potential to improve summer temperature reconstructions with earlywood information, Clim. Past, 10, 877-885, doi:10.5194/cp-10-877-2014, 2014.

Björklund, J., Gunnarson, B. E., Seftigen, K., Zhang, P., and Linderholm, H. W.: Using adjusted Blue Intensity data to attain highquality summer temperature information: A case study from Central Scandinavia, The Holocene, 25, 547-556, 2015.

Bojariu, R. and Giorgi, F.: The North Atlantic Oscillation signal in a regional climate simulation for the European region, Tellus A, 57, 641-653, 2005.

Briffa, K. R., Jones, P. D., Bartholin, T. S., Eckstein, D., Schweingruber, F. H., Karlen, W., Zetterberg, P., and Eronen, M.:
Fennoscandian summers from AD 500: temperature changes on short and long timescales, Clim. Dynam., 7, 111-119, 1992.

Briffa, K. R., Jones, P. D., Schweingruber, F. H., Karlén, W., and Shiyatov, S. G.: Tree-Ring Variables as Proxy-Climate Indicators: Problems with Low-Frequency Signals, Springer, 9-41, 1996.

Briffa, K. R., Osborn, T. J., Schweingruber, F. H., Harris, I. C., Jones, P. D., Shiyatov, S. G., and Vaganov, E. A.: Low-frequency temperature variations from a northern tree ring density network, J. Geophys. Res.-Atmos., 106, 2929-2941, 2001.

Busuioc, A., Chen, D., and Hellström, C.: Temporal and spatial variability of precipitation in Sweden and its link with the large scale atmospheric circulation, Tellus, 53A, 348-367, 2001.

Chen, D. and Hellström, C.: The influence of the North Atlantic Oscillation on the regional temperature variability in Sweden: spatial and temporal variations, Tellus A, 51, 505-516, 1999.

Cook, E. R. and Peters, K.: The Smoothing Spline: A New Approach to Standardizing Forest Interior Tree-Ring width Series for Dendroclimatic Studies, Tree-Ring Bulletin, 41, 45-53, 1981.

Cook, E. R., Briffa, K. R., Meko, D. M., Graybill, D. A., and Funkhouser, G.: The "segment length curse" in long treering chronology development for palaeoclimatic studies, The Holocene, 5, 229-237, 1995.

Cook, E. R., Krusic, P. J., and Melvin, T.: Program RCSsigFree: Version 45_v2b. Lamont-Doherty Earth Obs. Columbia University, 2014.

Esper, J., Frank, D. C., Timonen, M., Zorita, E., Wilson, R. J., Luterbacher, J., Holzkämper, S., Fischer, N., Wagner, S., and Nievergelt, D.: Orbital forcing of tree-ring data, Nat. Clim. Change, 2, 862-866, 2012.

Folland, C. K., Knight, J., Linderholm, H. W., Fereday, D., Ineson, S., and Hurrell, J. W.: The summer North Atlantic Oscillation: past, present, and future, J. Climate, 22, 1082-1103, 2009.

Frank, D., Esper, J., Zorita, E., and Wilson, R.: A noodle, hockey stick, and spaghetti plate: a perspective on high-resolution paleoclimatology, Wiley Interdisciplinary Reviews: Climate Change, 1, 507-516, 2010.

Fritts, H.: Tree Rings and Climate, Academic Press Inc. (London) Ltd., London, UK, 1976.

Gordon, G.: Verification of dendroclimatic reconstructions, in: Climate from tree rings, edited by: Hughes, M. K., Kelly, P. M., Pilcher, J. R., LaMarche, V. C., and Pilcher, J. R., Cambridge University Press, Cambridge, 58-61, 1982.

Graham, R., Robertson, I., McCarroll, D., Loader, N., Grudd, H., and Gunnarson, B.: Blue Intensity in Pinus sylvestris: application, validation and climatic sensitivity of a new palaeoclimate proxy for tree ring research, in: AGU Fall Meeting Abstracts, 1, 9-41, 2011.

Grove, J. M.: The Initiation of the "Little Ice Age" in Regions Round the North Atlantic, in: The Iceberg in the Mist: Northern Research in pursuit of a "Little Ice Age", Springer, 53-82, 2001.

Grove, J. M. and Switsur, R.: Glacial geological evidence for the Medieval Warm Period, Clim. Change, 26, 143-169, 1994.

Grudd, H., Briffa, K. R., Karlén, W., Bartholin, T. S., Jones, P. D., and Kromer, B.: A 7400-year tree-ring chronology in northern Swedish Lapland: natural climatic variability expressed on annual to millennial timescales, The Holocene, 12, 657-665, 2002. 
Gunnarson, B. E.: Temporal distribution pattern of subfossil pines in central Sweden: perspective on Holocene humidity fluctuations, The Holocene, 18, 569-577, 2008.

Gunnarson, B. E., Borgmark, A., and Wastegård, S.: Holocene humidity fluctuations in Sweden inferred from dendrochronology and peat stratigraphy, Boreas, 32, 347-360, 2003.

Gunnarson, B. E., Linderholm, H. W., and Moberg, A.: Improving a tree-ring reconstruction from west-central Scandinavia: 900 years of warm-season temperatures, Clim. Dynam., 36, 97-108, 2011.

Gunnarson, B. E., Josefsson, T., Linderholm, H. W., and Östlund, L.: Legacies of pre-industrial land use can bias modern tree-ring climate calibrations, Clim. Res., 53, 63-76, 2012.

Harris, I., Jones, P., Osborn, T., and Lister, D.: Updated high resolution grids of monthly climatic observations - the CRU TS3.10 Dataset, Int. J. Climatol., 34, 623-642, 2014.

Helama, S., Lindholm, M., Timonen, M., Meriläinen, J., and Eronen, M.: The supra-long Scots pine tree-ring record for Finnish Lapland: Part 2, interannual to centennial variability in summer temperatures for 7500 years, The Holocene, 12, 681-687, 2002.

Helama, S., Mielikäinen, K., Timonen, M., and Eronen, M.: Finnish supra-long tree-ring chronology extended to 5634 BC, Norw. J. Geogr., 62, 271-277, 2008.

Helama, S., Fauria, M. M., Mielikäinen, K., Timonen, M., and Eronen, M.: Sub-Milankovitch solar forcing of past climates: mid and late Holocene perspectives, Geol. Soc. Am. Bull., 122, 19811988, 2010.

Helama, S., Vartiainen, M., Holopainen, J., Mäkelä, H. M., Kolström, T., and Meriläinen, J.: A palaeotemperature record for the Finnish Lakeland based on microdensitometric variations in tree rings, Geochronometria, 41, 265-277, 2014.

Irannezhad, M., Chen, D., and Kløve, B.: Interannual variations and trends in surface air temperature in Finland in relation to atmospheric circulation patterns, 1961-2011, Int. J. Climatol., 35, 3078-3092, 2014.

Johannessen, T. W.: The climate of Scandinavia, Climates of Northern and Western Europe, World Survey of Climatology, 5, 23-80, 1970.

Johansson, B. and Chen, D.: The influence of wind and topography on precipitation distribution in Sweden: Statistical analysis and modelling, Int. J. Climatol., 23, 1523-1535, 2003.

Lamb, H. H.: Climatic fluctuations, World Survey of Climatology, 2, 173-249, 1969.

Linderholm, H. W., Solberg, B. Ø., and Lindholm, M.: Tree-ring records from central Fennoscandia: the relationship between tree growth and climate along a west-east transect, The Holocene, 13, 887-895, 2003.

Linderholm, H. W., Björklund, J. A., Seftigen, K., Gunnarson, B. E., Grudd, H., Jeong, J.-H., Drobyshev, I., and Liu, Y.: Dendroclimatology in Fennoscandia - from past accomplishments to future potential, Clim. Past, 6, 93-114, doi:10.5194/cp-6-93-2010, 2010 .

Linderholm, H. W., Zhang, P., Gunnarson, B. E., Björklund, J., Farahat, E., Fuentes, M., Rocha, E., Salo, R., Seftigen, K., and Stridbeck, P.: Growth dynamics of tree-line and lake-shore Scots pine (Pinus sylvestris L.) in the central Scandinavian Mountains during the Medieval Climate Anomaly and the early Little Ice Age, Paleoecology, 2, 20, doi:10.3389/fevo.2014.00020, 2014.
Linderholm, H., Björklund, J., Seftigen, K., Gunnarson, B., and Fuentes, M.: Fennoscandia revisited: a spatially improved tree-ring reconstruction of summer temperatures for the last 900 years, Clim. Dynam., 45, 933-947, 2015.

Lundqvist, J.: Beskrivning till jordartskarta över Jämtlands län: 4 Karten. Kt, Sveriges Geologiska Undersökning, 1969.

Luterbacher, J., Werner, J. P., Smerdon, J. E., FernáándezDonado, L., González-Rouco, F. J., Barriopedro, D., Ljungqvist, F. C., Büntgen, U., Zorita, E., Wagner, S., Esper, J., McCarroll, D., Toreti, A., Frank, D., Jungclaus, J. H., Barriendos, M., Bertolin, C., Bothe, O., Brázdil, R., Camuffo, D., Dobrovolný, P., Gagen, M., García-Bustamante, E., Ge, Q., Gómez-Navarro, J. J., Guiot, J., Hao, Z., Hegerl, G. C., Holmgren, K., Klimenko, V. V., Martín-Chivelet, J., Pfister, C., Roberts, N., Schindler, A., Schurer, A., Solomina, O., von Gunten, L., Wahl, E., Wanner, H., Wetter, O., Xoplaki, E., Yuan, N., Zanchettin, D., Zhang, H., and Zerefos, C.: European summer temperatures since Roman times, Environ. Res. Lett., 11, 024001, doi:10.1088/1748-9326/11/2/024001, 2016.

Matskovsky, V. V. and Helama, S.: Testing long-term summer temperature reconstruction based on maximum density chronologies obtained by reanalysis of tree-ring data sets from northernmost Sweden and Finland, Clim. Past, 10, 1473-1487, doi:10.5194/cp10-1473-2014, 2014.

McCarroll, D., Loader, N. J., Jalkanen, R., Gagen, M. H., Grudd, H., Gunnarson, B. E., Kirchhefer, A. J., Friedrich, M., Linderholm, H. W., and Lindholm, M.: A 1200-year multiproxy record of tree growth and summer temperature at the northern pine forest limit of Europe, The Holocene, 0, 1-14, 2013.

Melvin, T. M.: Historical Growth Rates and Changing Climatic Sensitivity of Boreal Conifers, University of East Anglia, Norwich, UK, 2004.

Melvin, T. M. and Briffa, K. R.: A "signal-free" approach to dendroclimatic standardisation, Dendrochronologia, 26, 71-86, 2008.

Melvin, T. M. and Briffa, K. R.: CRUST: Software for the implementation of regional chronology standardisation: part 1. Signalfree RCS, Dendrochronologia, 32, 7-20, 2014a.

Melvin, T. M. and Briffa, K. R.: CRUST: Software for the implementation of Regional Chronology Standardisation: Part 2. Further RCS options and recommendations, Dendrochronologia, 32, 343-356, 2014b.

Melvin, T. M., Grudd, H., and Briffa, K. R.: Potential bias in "updating" tree-ring chronologies using regional curve standardisation: re-processing 1500 years of Torneträsk density and ringwidth data, The Holocene, 23, 364-373, 2013.

National Research Council: Surface Temperature Reconstructions for the Last 2000 Years, The National Academies Press: Washington, DC, 160 pp., 2006.

PAGES 2k Consortium: Continental-scale temperature variability during the last two millennia, Nat. Geosci., 6, 339-346, 2013.

Rodwell, M. and Folland, C.: Atlantic air-sea interaction and seasonal predictability, Q. J. Roy. Meteor. Soc., 128, 1413-1443, 2002.

Rodwell, M., Rowell, D., and Folland, C.: Oceanic forcing of the wintertime North Atlantic Oscillation and European climate, Nature, 398, 320-323, 1999.

St. George, S.: An overview of tree-ring width records across the Northern Hemisphere, Quaternary Sci. Rev., 95, 132-150, 2014. 
Stocker, T., Qin, D., Plattner, G., Tignor, M., Allen, S., Boschung, J., Nauels, A., Xia, Y., Bex, V., and Midgley, P.: IPCC, 2013: summary for policymakers, in: Climate Change 2013: The Physical Science Basis, Contribution of Working Group I to the Fifth Assessment Report of the Intergovernmental Panel on Climate Change, Cambridge Univ. Press, Cambridge, UK, 3-29, 2013.

Tuomenvirta, H., Drebs, A., Førland, E., Tveito, O. E., Alexandersson, H., Laursen, E. V., and Jónsson, T.: Nordklim data set 1.0 description and illustrations, Tech. rep., DNMI Report, 2001.

van Oldenborgh, G. J., Drijfhout, S., van Ulden, A., Haarsma, R., Sterl, A., Severijns, C., Hazeleger, W., and Dijkstra, H.: Western Europe is warming much faster than expected, Clim. Past, 5, 112, doi:10.5194/cp-5-1-2009, 2009.

Wallén, C. C. (Ed.): Climates of Northern and Western Europe, Elsevier, Amsterdam, 1970.

Wigley, T. M., Briffa, K. R., and Jones, P. D.: On the average value of correlated time series, with applications in dendroclimatology and hydrometeorology, J. Clim. Appl. Meteorol., 23, 201-213, 1984.
Wilson, R. J. S., Anchukaitis, K., Briffa, K., Büntgen, U., Cook, E. R., D’Arrigo, R., Davi, N., Esper, J., Frank, D., Gunnarson, B., Hegerl, G., Helama, S., Klesse, S., Krusic, P. J., Linderholm, H. W., Myglan, V., Osborn, T., Rydval, M., Schneider, L., Schurer, A., Wiles, G., Zhang, P., and Zorita, E.: Last millennium northern hemisphere summer temperatures from tree rings: Part I: The long term context, Quaternary Sci. Rev., 134, 1-18, 2016.

Yang, B., Qin, C., Wang, J., He, M., Melvin, T. M., Osborn, T. J., and Briffa, K. R.: A 3500-year tree-ring record of annual precipitation on the northeastern Tibetan Plateau, Proc. Natl. Acad. Sci., 111, 2903-2908, 2014.

Zhang, P., Björklund, J., and Linderholm, H. W.: The influence of elevational differences in absolute maximum density values on regional climate reconstructions, Trees, 29, 1259-1271, 2015. 